\title{
JOSE DE LANZ, UN MEXICANO AL SERVICIO DE LAS PROVINCIAS UNIDAS DEL RIO DE LA PLATA Y DE LA GRAN COLOMBIA (1816-1827)
}

\section{INTRODUCCIÓN}

Debo comenzar estas notas con una imprescindible referencia historiográfica porque, más allá de la significación de los hechos que aquí se han de exponer, interesa señalar ciertas constantes en las historias nacionales que se han escrito sobre nuestros países latinoamericanos.

Hacia comienzos de este siglo, el historiador Carlos Villanueva publicó algunos datos sobre la gestión que José de Lanz llevó a cabo en París por encargo del gobierno de la Gran Colombia. Concretamente, refirió este autor que el conde de Villele, presidente del Consejo francés, hizo conocer a Lanz que Francia había renunciado a toda agresión contra la nueva nación independiente, desentendiéndose así de las presiones de la Santa Alianza. Decisión tan importante para la suerte de las revoluciones hispanoamericanas fue comunicada por Lanz al ministro de Relaciones Exteriores grancolombiano, Pedro Gual; éste, animado por la noticia, instruyó a Lanz para que promoviera un acuerdo con Francia en condiciones similares a las ya concertadas con Gran Bretaña. Con estas referencias, Villanueva presentó a Lanz al conocimiento histórico hispanoamericano. ${ }^{1}$

Tiempo después, el historiador colombiano Diego Mendoza agregó algunos datos sobre la misión de Lanz en un breve y sustancioso artículo publicado en una revisıa londinense. Mendoza aportó

1 Villanueva, Carlos A.: La monarquía en América. La Santa Alianza. París, s/a., passim. 
alguna información biográfical, por ejelipio, que había estado en Buenos Aires contratado por Rivadavia como científico y que, disgustado por los conflictos políticos internos que allí encontró, decidió regresar a Francia; el autor hacía referencia también a los servicios que Lanz prestó a la Gran Colombia, de lo que hemos de tratar más adelante. ${ }^{2}$

Un cuarto de siglo después -ya en 1938- el historiador argentino Diego Luis Molinari dio a conocer en un erudito estudio que en 1816, con motivo de la gestión diplomática que su gobierno le había encomendado en Europa, Rivadavia contrató a un profesor de ciencias exactas y naturales, el «catalán José Lanz», quien viajó a la capital rioplatense y se vinculó al director Puyrredón. Según esta versión, que inás adelante corregiremos, el profesor informó al gobernante porteño sobre las tentativas diplomáticas que se realizaban en Europa, y éste le encargó que por escritura cifrada le comunicara a Rivadavia la declaración de la independencia y el deseo del gobierno de que el comisionado se mantuviera en la capital francesa; refería luego que Lanz regresó de Buenos Aires a Francia portando oficios y comunicaciones del gobierno. ${ }^{3}$ Luego, Cárcano recogería esta versión y la vertería en un breve párrafo de su voluminosa obra sobre la historia diplomática argentina. ${ }^{4}$

Pocos años después del estudio de Molinari, en Colombia el historiador Francisco José Urrutia refirió que en 1824 el gobierno de la Gran Colombia designó a José María Lanz como su agente confidencial en Francia. Debía gestionar el reconocimiento de la independencia, informar al gobierno francés sobre los sentimientos pacíficos de los colombianos, promover la apertura y sondear la actitud de ese gobierno ante la proyectada acción militar de Colombia en Puerto Rico y Cuba. ${ }^{5}$

2 Mendoza, Diego: Misión de José María Lanz. En «Hispania, Política, Comercio, Literatura, Artes y Ciencias», Año II, vol. II, núm. 19. Londres. 1 de julio de 1913, págs. 660-662.

3 Molinari, Diego Luis: Fernando VII y la emancipación de América (1814-1819). En «Segundo Congreso Internacional de Historia de América», tomo IV: Buenos Aires, 1938, pág. 347.

4 Carcano, Miguel Angel: La política internacional en la historia arventina. Buenos Aires, 1972-1973, pág. 672.

5 Urrutia, Francisco José: Politica internacional de la Gran Colombia. Bogota. 1941. 
Obviamente, el Lanz de Villanueva, Mendoza y Urrutia es el mismo Lanz de Molinari y Cárcano; sin embargo, los unos y los otros lo han tratado como si fueran diferentes personas. La dirección de los estudios históricos en Argentina y Colombia ha impedido, así, que sus gestiones diplomáticas, al servicio de uno y otro país en diferentes momentos de la revolución de independencia hispanoamericana -en un lapso de ocho años-, fuesen vinculadas entre sí, y esto es lo que hemos querido resaltar en esta suerte de contrapunto de sucesivas referencias historiográficas.

Es obvio también que la vinculación no ha sido establecida por la simple razón de que los historiadores de cada nación involucrada sólo han conocido la misión referida a su país, que era la que concitaba su atención. La ignorancia no va en demérito individual de quienes, aquí y allá, se ocuparon de Lanz, sino de una tradición generalizada del enfoque y perspectiva de la historia que no ha superado aún una cerrada dimensión nacional. Es claro que si estuviera desarrollada la historia general del continente, y en especial la historia de los pueblos hispanoamericanos en lo que tienen de común, existirían otras posibilidades de que esas vinculaciones fuesen más fácilmente detectadas a través de la documentación y de la bibliografía históricas. $Y$ en tal caso, esta modesta introducción no hubiera tenido razón de ser.

Pero he aquí que nosotros mismos - que ahora venimos en el rol de correctores-, hemos cometido esta misma comisión años atrás, en ocasión de estudiar los trabajos de Lanz como científico y diplomático al. servicio del gobierno de Buenos Aires. "Este opúsculo tiene su razón de ser, en parte, en la necesidad de reparar aquella omisión propia.

¿Cuál es el sentido que tiene presentar ahora, como en un mural, los dos retazos? ¿Qué interés tiene para la historia de Colombia y Venezuela lo que Lanz hizo al servicio de Argentina, y viceversa? Quizá luego de concluir la lectura de este trabajo, algunos se mantengan en la incertidumbre. Y puede ocurrir que así

6 Heredia, Edmundo A.: España y la independencia del Rio de la Plata. Capitulos de su historia. Córdoba, 1977.

Tomo XLVII 
sea porque aún la historia de Hispanoamérica, como una unidad, aparece como una abstracción, una empresa a realizar, un proyecto para el que no hemos encontrado todo su sentido y su valor intrínseco, aunque al menos hemos comenzado a vislumbrarlo.

La respuesta - nuestra respuesta - es que es ésta una parte, posiblemente menor y secundaria, de la historia de nuestra América que estamos buscando. Ojalá este pequeño aporte contribuya a que un día esta historia tenga un sentido tan profundo como puede tenerlo la historia de cada nación para los ciudadanos de cada una de ellas. Y ojalá que alguna vez la unión de todos los fragmentos - como los dos que ahora se exponen - llegue a dotar de un sentido de unidad a este grande y complejo universo hispanoamericano. Tenemos la intuición que será un paso firme para tomar conciencial de lo que somos a partir de lo que fuimos, y entonces sus pueblos se sentirán más cerca unos de otros.

\section{LA ETAPA RIOPLATENSE}

\section{El científico José de Lanz}

José de Lanz había nacido en Michoacán (México), hacia 1770. Sus padres, de acomodada posición, lo enviaron aún niño a estudiar a la capital española. Se trasladó luego a París, y allí debió ganarse su sustento, pues la situación de su familia había dejado de ser próspera. Mientras trabajaba como operario en una fábrica, estudió matemáticas generales y aplicadas. De regreso a Madrid, intervino en la corrección y construcción de la carta geográfica de España. Hacia comienzos del siglo XIX era ya un experto reconocido, y pudo así fundar una escuela especial de mecánica. ${ }^{7}$

Debió tener también inquietudes políticas, de las que, por lo demás, era difícil sustraerse en la agitada Europa de entonces. Establecido el poder francés en la capital de España, se enroló en

7 En estas referencias biográficas reproducimos los datos que provee el utilísimo Diccionario de Cutolo. V. Cutolo, Vicente Osvaldo: Nuevo Diccionario Biográfico Argentino (1750-1930). Buenos Aires, 1975. 
las filas de José Bonaparte; restaurado el absolutismo en España, tuvo que regresar a Francia. Cuando el imperio napoleónico cayó se asiló en Inglaterra, y allí fue donde conoció a Rivadavia; es entonces cuando comienza nuestra historia.

Había publicado ya, junto con Agustín de Bethencourt y Molina, el Essai sur le composition des machines, lo que indica la orientación de sus estudios. El libro tuvo suceso, pues a la primera edición de 1808 le sucedería una segunda, en 1819. El coautor era un matemático e ingeniero español, de Canarias, cuya actividad se había desarrollado en Rusia, adonde fue llamado por el zar Alejandro, quien lo hizo allí teniente general del ejército imperial; Bethencourt creó en Rusia un Colegio Militar de Ingenieros y una Escuela de Ciencias Exactas, cumpliendo así una trayectoria muy parecida a la que llevaría a cabo Lanz en América.

\section{La dirección de la Academia de Matemáticas en Buenos Aires}

A fines de 1814 el Directorio de las Provincias Unidas del Río de la Plata comisionó a Bernardino Rivadavia y a Manuel Belgrano a Río de Janeiro y Cortes europeas. Esta misión, ya prolijamente estudiada, estaba dirigida a contener los impulsos reconquistadores de España, tanto en gestiones directas como en tentativas mediadoras con otras potencias. Al mismo tiempo que desenvolvían sus largas y arduas tareas diplomáticas, Rivadavia y Belgrano procuraron concretar los ideales progresistas que los inspiraban: el fomento de la enseñanza y difusión de las ciencias y las artes en las Provincias Unidas. Un objetivo particular de este programa era formar expertos en la fabricación de pertrechos de guerra, ya que la situación revolucionaria reclamaba que esos estudios tuvieran una urgente aplicación práctica.

Por encargo del director -entonces Carlos de Alveal- el secretario de gobierno Nicolás Herrera había encomendado a los comisionados la contratación de profesores de matemáticas en Europa. Debían ser preferidos los de nacionalidad española, por 
la ventaja del idioma común, y se les debía asegurar que gozarían en su destino de una buena acogida y de especial consideración. Les facilitarían todos los auxilios necesarios para su traslado a Buenos Aires. ${ }^{8}$

Rivadavia asumió la tarea con convicción y sus frutos fueron alcanzados a comienzos de 1816; encontró la persona indicada en José de Lanz, quien seguramente estaba entonces en incómoda posición, debido a la persecución de que eran objeto los partidarios del derrotado Napoleón Bonaparte.

Por el contrario, la situación en Buenos Aires debía aparecer promisoria a las expectativas del científico. Luego de varios años de gobiernos inestables y efímeros, en que no pudo imponerse un sistema de conducción definido, se había iniciado allí la época directorial, cuya meta era organizar la nueva nación y dotarla de una constitución. El Reglamento del Directorio garantizaba libertades individuales, y sus dirigentes demostraban encomiable vocación por el orden y el firme propósito de cultivar y desarrollar el conocimiento y aplicación de las ciencias.

Si en el orden interno y desde aquella óptica eran halagüeñas las perspectivas, también era privilegiada la situación de estas Provincias Unidas en su lucha por la emancipación. A diferencia de los demás países hispanoamericanos en estado de insurrección, la fuerza española estaba lejos de poder amenazar la zona rioplatense. A mediados de 1814 habían sido batidos los realistas de Montevideo y, en lugar de armarse para defender la capital, los revolucionarios se lanzaban entonces a extender el movimiento emancipador al otro lado de la cordillera de los Andes. Gobierno independiente consolidado y organizado, y la euforia de una revolución triunfante, debieron ser las apreciaciones de Lanz al evaluar lo que podía esperar en el Plata.

En sus conversaciones con Rivadavia y Belgrano supo, además, que el primero sería recibido en la Corte española, y el optimismo

8 De Herrera a Belgrano y Rivadavia. Buenos Aires, 21 de diciembre de 1814. En Comisión de Bernardino Rivadavia ante España y otras potencias de Europa (1814-18ट0). Buenos Aires, 1933-1936. (En adelante, C.B.R.), tomo II, págs. 257-258, doc. 298. 
con que los dos comisionados veían esta gestión debió ser otro factor que infundió confianza al matemático sobre los días venturosos que le esperaban en Buenos Aires.

Rivadavia convino con Lanz que éste desempeñaría el cargo de director y primer profesor de Ciencias Exactas y Naturales de la Academia de Matemáticas de Buenos Aires. Se comprometió a que el gobierno le diese alojamiento en la propia casa de la Academia y le abonase un sueldo proporcionado a la jerarquía de sus trabajos; recibiría también en su destiro el importe de los pasajes de él y de su esposa, del cual Rivadavia adelantó parte al dueño del buque en que se embarcaron. ${ }^{9}$

Desconociendo el gobierno los resultados obtenidos por el comisionado, por los mismos días en que éste concluía el acuerdo con Lanz en Europa se nombraba en Buenos Aires a Felipe Senillosa en el mismo cargo de director de la Academia y de preceptorde Matemáticas, con un sueldo de 800 pesos. ${ }^{10}$ Senillosa era un catalán que por entonces incursionaba en el periodismo, y que había estudiado Matemáticas en la Universidad de Alcalá de Henares; luego de prestar servicios en España como militar c ingeniero, se había trasladado a Londres, donde conoció a Rivadavia y Belgrano. Trasladado a Buenos Aires por. sugestión de éstos, pasó a redactar el periódico «Los Amigos de la Patria y de la Juventud».

Obviamente, el nombramiento de Senillosa se superponía al de Lanz. No obstante, al arribo del segundo la situación quedó resuelta con el desplazamiento de Senillosa al cargo de segundo director, elevando en compensación sus haberes a 1.000 pesos. " El recién llegado fue confirmado como director, con lal facultal

9 De Rivadavia al director Alvarez Thomas. Paris, 4 de febrero de 1816. En C.B.R., tomo II, págs. 258-259, doc. 299.

10 Archivo General de la Nación, Buenos Aires. (En adelante, A.G.N.A.), X-8-9-4. Libro 78 de Despachos. Títulos y Cédulas, fol. 295. Despacho del director supremo. Buenos Aires, 3 de febrero de 1816.

11 Despacho del director supremo. Buenos Aires, 17 de agosto de 1816. X-8-9-4. Libro 78 de Despachos, Títulos y Cédulas, fol. 297. La Academia do Matemáticas funcionaba bajo la dependencia del Consulado de Buenos Aires. Senillosa había sido designado en reemplazo de Manuel Herrera, pero éste había permanecido sólo cinco meses en el cargo. V. Tjorks, Germán O. E.: El Con sulado de Buenos Aires y sus proyecciones en la historia del Rio de la Plata. Buenos Aires, 1962. 
de arreglar el plan de estudios en todos sus aspectos, y sc le asignó un sueldo de 1.500 pesos anuales. ${ }^{12}$

El ambiente porteño no deparó a Lanz todas las satisfacciones que había vislumbrado. El Consulado comenzó protestando al gobierno por la designación directa, porque consideraba que ella era una atribución suya. Pero esto no obstó para que el matemático asumiera la dirección y se granjeara pronto el respeto y la consideración de las autoridades, seguramente por sus relevantes antecedentes intelectuales, que lo destacaban en un medio en el que los estudios científicos eran incipientes. ${ }^{13}$

Su primera tarea como director fue la de elaborar el Reglamento de la Academia, por lo que se deduce que con su designación esta institución inició una nueva y más orgánica etapa, que concluiría al incorporarse ésta a la Universidad de Buenos Aires, en 1821. Lanz acompañó el Reglamento con una exposición en la que señalaba los beneficios de la enseñanza de las matemáticas. Consideraba que el estudio de estas ciencias es lo que confiere mayor dignidad al hombre, pues «dan solidez al juicio, estensión y profundidad al entendimiento, y la costumbre preciosísima de admitir únicamente lo demostrable, abandonando las hipótesis, y los sistemas especiosos, fundado ya en tradiciones vagas, ya en suposiciones brillantes». Los grandes adelantos logrados en la navegación, en la arquitectura naval, en la invención y perfeccionamiento de máquinas los atribuía a los conocimientos de las matemáticas y de otras disciplinas que de ellas directamente derivan. Su estudio, en fin, conducía a formar buenos ciudadanos, útiles a la patria.

En cuanto al Reglamento, éste era presentado con carácter provisional, pues el Directorio tenía el propósito de dar mayor extensión a los estudios de la Academia cuando las circunstancias lo permitieran. En tal caso, Lanz entendía que debían fijarse ma-

12 A.G.N.A., X-8-9-4. Libro 78 de Despachos, Títulos y Cédulas, fol. 296. Despacho del director supremo. Buenos Aires, 17 de agosto de 1816.

13 Las primeras referencias sobre su actividad al frente de la Academia se deben a los notables estudios de Juan María Gutiérrez. V.: Crónica del desarrollo de las ciencias matemáticas y de observación en el Río de la Plata. En «Revista Nacional», Año I, tomo II, Buenos Aires, 1886; Noticias históricas sobre el orijen $y$ desarrollo de la enseñanza pública superior en Buenos Aires. Buenos Aires, 1868. 
yores requisitos para el ingreso y aumentar los años de estudio para introducir los principios de la física y de la química, «tan. necesarios - decía-, sobre todo en un país donde las artes están aún en la infancia y donde el reino mineral of rece tantas riquezas».

El Reglamento fue elevado a consideración del director el 11 de octubre de 1816, y sería publicado por el Consulado en la Imprenta del Sol, el mismo año. ${ }^{14}$ En él se indicaban las condiciones para el ingreso -12 a 16 años de edad, saber leer y escribir, $v$ conocer las cuatro reglas aritméticas-; se fijaban los horarios de clase, de prácticas, de estudios; la duración del curso — dos años, en períodos desde marzo a diciembre-. El Consulado seleccionaría los candidatos, y los exámenes serían públicos. El director de la Academia podía aplicar suspensiones de hasta tres días, y para sanciones más severas debía someter los antecedentes al Consulado. ${ }^{15}$

Lanz asumió así la dirección del renovado instituto, en el que se granjeó considerable estima. Gutiérrez juzgaría que «su permanencia fue corta, pero honrosa y útil para el país». Uno de sus discípulos, Marcos Chiclana, referiría luego a Gutiérrez datos biográficos de Lanz, ponderando sus valores y el aprecio a que se hizo merecedor.

Lanz agregaría otro servicio a la enseñanza de las ciencias en Argentina, al traducir del francés al castellano el libro Elementos de Aritmética, de J. F. Lacroix. Para su décimotercera edición fue abierta una suscripción por la Imprenta del Sol. ${ }^{16}$

\section{La misión secreta}

Además del objeto señalado, Lanz vino de Europa con encargos secretos de Rivadavia, relacionados con la comisión que éste desempeñaba ante las Cortes curopeas. Las precauciones para man-

14 Fue reproducido en el libro de Gutiérrez, J. M.: Noticias histórica.s..., págs. 209-213.

15 Tjarks, en El Consulado.... señala que el Reglamento se basó parcialmente en el de Belgrano, de 1799.

16 Así lo anunció «La Crónica Argentina» en su edición núm. 19 del 30 de septiembre de 1816. Según ese anuncio, la publicación era «para el uso de las Academias de matemáticas en Buenos Aires». 
tener el sigilo fueron extremas, y algunos detalles no se asentaron por escrito sino que fueron confiados exclusivamente a la palabra oral. Esto prueba que el matemático había ganado la confianzal del comisionado, puesto que le participó sus más reservadas gestiones y dio por segura su correcta información al gobierno de Buenos Aires.

A Manuel García, que representaba a las Provincias Unidas en la Corte de Río de Janeiro, envió Rivadavia dos cartas por intermedio de Lanz; una de ellas sería entregada en el puerto de la capital brasileña a una tercera persona, para que ésta la alcanzara al destinatario. ${ }^{17}$ En ella Rivadavia recomendaba a García que fuera a ver a Lanz en el barco; cuando así lo hiciera, el viajero le entregaría la segunda misiva, que debió contener la sustancia de los informes que el comisionado quería hacer llegar a su colega. ${ }^{18}$ El celo puesto en la entrega de esta correspondencia en la escala fluminense parece evidenciarse también en los términos usados para designar al intermediario: en la primera se mencionaba a Lanz como «portador» y en la segunda como «dador», sutileza que bien puede ser producto del riguroso cuidado que tuvo Rivadavia. ${ }^{19}$

Sin embargo, la epístola que entregó en manos de García no abundaba en detalles: en ella Rivadavia anunciaba que se presentaría en la Corte española; la mayor extensión era para recomendar al científico y pedir la colaboración de García en la etapa final de su viaje. ${ }^{20}$ Lo significativo es que aquí Rivadavia anunció que Lanz le daría a conocer verbalmente todas las novedades; un mes después, ante el reclamo de García, Rivadavia le diría que lo intere-

17 De Rivadavia a Garcia. París, 4 de febrero de 1816. En C.B.R., tomo II, pág. 176, doc. 262 .

18 De Rivadavia a García. París, 1 de Pebrero de 1816. En C.B.R., tomo II, págs. 172-175, doc. 261 .

19 En tanto «portador» es el que «lleva o trae una cosa de una parte a otra». dador es quien klleva una carta de un sujeto a otro»; la segunda carta, pues, debia ser entregada en mano de su destinatario, no asi necesariamente la primera.

20 Esa colaboración no era otra que un subsidio pecuniario para atender las necesidades de Lanz, lo que hizo notar García cuando reclamó a su gobierno mayores recursos para atender sus compromisos oflciales. De García a Antonio González Balcarce. Río de Janeiro, 9 de junio de 1816. En Museo Mitre. Documentos del Archivo de Belgrano. Buenos Aires, 1917, tomo VII, pág. 104. 
sante era lo transmitido por Lanz, ${ }^{21}$ y más tarde que había cumplido lo que éste le había anticipado, es decir sus gestiones en Madrid. ${ }^{22}$ Queda claro entonces que debió referir a García todas las relaciones previas - mantenidas en secreto entonces- entre la Corte española y el enviado porteño, en las que actuó como mediador Juan Manuel de Gandasegui, y para ello se provocó la visita de García a Lanz en el barco. Los recaudos para mantener el secreto en Río de Janeiro se justificaban por la expectativa que la actitud de Rivadavia despertaba en la Corte brasileña y en el influyente embajador británico, lord Strangford.

El hecho de que Lanz fuese el mensajero oral de las cruciales negociaciones rivadavianas en Europa, indican que estaba ya involucrado en la actividad diplomática rioplatense, dedicada entonces a sostener la causa de la independencia de la nueva nación. Como se sabe, estas gestiones debían estar rodeadas de la mayor cautela, pues se trataba de no provocar reacciones belicistas de España, cuyo gobierno desplegaba por entonces laboriosas gestiones ante las Cortes europeas para desbaratar los acercamientos diplomáticos de los revolucionarios.

Lanz cumplió aún una tarea más delicada, como fue la de entregar el sistema cifrado que Rivadavia envió al director y a Manuel García para las futuras comunicaciones secretas; es posible que esta documentación haya sido destruida luego de ser conocida por los destinatarios, pues no se encuentra en los legajos de la misión existentes en el Archivo General de la Nación de Argentina, ni ha sido recogida en la colección documental presentada por Emilio Ravignani. Por ahora, lo que interesa destacar aquí es el papel especial y de suma confianza que cupo a Lanz como portador de las cifras. El código fue participado a Manuel García, como se desprende de la carta de Rivadavia en que le pide mayores informaciones «por el medio que le habrá entregado Dn. J. L.». ${ }^{23} \mathrm{Tal}$ medio no podía ser otro que el utilizado en las comunicaciones entre

21 A.G.N.A., X-1-1-4. De Rivadavia a García. París, 18 de marzo de 1816.

22 De Rivadavia a García. I'aris, 20 de septiembre de 1816. En C.B.R., tomo II, págs. $178-182$, doc. 264.

23 De Rivadavia a García. Paris, 18 de marzo de 1816. En C.B.R., tomo II, págs. 177-178, doc. 263. 
Rivadavia y el director, y al que se alude concretamente en carta del primero. ${ }^{24}$

Con el transcurso de los meses y estrechada la vinculación con el director Pueyrredón, Lanz obtuvo de éste aún mayores pruebas de confianza, pues pasó a ser depositario de la cifra utilizada para las comunicaciones secretas con Rivadavia, para llegar luego a ser el corresponsal oficial del director en sus relaciones con el comisionado en Europa; esto es, Lanz escribía a Rivadavia, en cifra, lo que le encomendaba Pueyrredón. ${ }^{25}$

Lanz fue quien anunció al enviado la declaración de la independencia en Tucumán - que, como se sabe, no se proclamó a los demás países, por precaución, hasta mediados de 1817- y la orden de mantenerse en París a la espera de nuevas órdenes del gobierno. ${ }^{2 n}$

Rivadavia mostró algunos reparos en aceptar las cartas de Lanz como correspondencia oficial, pero terminó por resignarse; le molestaba también la informalidad de los términos, por lo quic él siguió dirigiendo las respuestas a Pueyrredón y guardando las fórmulas oficiales de estilo. ${ }^{27}$

El comisionado reavivaría sus recelos contra el ahora confidente de Pueyrredón cuando se enterara, por palabras de su esposa, que Lanz viajaba de regreso a París y que era portador del duplicado de la orden de su regreso a la patria. ${ }^{28}$

No pudo ocultar entonces su profundo desagrado, desconfiando sobre los motivos del abandono del cargo de director de la Academia, para lo cual lo había contratado; en efecto, el mexicano regresaba pocos meses después de haber asumido esa dirección, contradiciendo las intenciones del convenio. Aunque Lanz no dio mayores explicaciones sobre los motivos de su regreso, parece cierto

24 De Rivadavia a Pueyrredón. París, 16 de octubre de 1816. En C.B.R., tomo I, págs. 163-164, doc. 68 .

25 Ibidem.

26 De Rivadavia a Pueyrredón, París, 26 de diciembre de 1816. En C.B.R., tomo I, págs. 180-188, doc. 73 .

27 De Rivadavia a Pueyrredón. París, 21 de octubre de 1816. En C.B.R.. tomo I, págs. 166-167, doc. 60 .

28 De Rivadavia a Pueyrredón. París, 4 de mayo de 1817. En C.B.R., tomo I. págs. 226-227, doc. 79. Lanz había renunciado a la Dirección de la Academia el 23 de enero de 1817 , según lo registra Tjarks. 
que se reunieron varios factores. Uno de ellos era que sus expectativas iniciales en cuanto a encontrar un país tranquilizado donde el cultivo de las ciencias fuese posible, quedaron defraudadas. La oposición a Pueyrredón se había recrudecido en los meses de su permanencia en Buenos Aires; al encarcelamiento y posterior extrañamiento de Dorrego habían seguido los de Manuel Moreno y muchos otros. El ambiente porteño se convulsionaba con estas noticias, la opinión se agitaba por la acción de una prensa combativa, y al peligro de las incursiones artiguistas en el litoral se sumaba el temor de una expedición española sobre el Plata. Por último, en esos meses se había producido la invasión lusitana a la Banda Oriental, lo que no había provocado resistencia del Directorio, sino antes bien un alivio por lo que significaba de contención a los opositores del centralismo. Lanz no debió ser testigo indiferente de esta conflictiva situación. Otro factor coadyuvante debió ser la falta de adaptación de su esposa al ambiente porteño, por cuanto, como lo apunta Gutiérrez, era «estraña a la lengua española y a nuestros usos y costumbres».

El inesperado regreso de Lanz, y el hecho de que portara la resolución que relevaba de su misión a Rivadavia, pudieron hacer sospechar a éste que ese relevo estaba vinculado con el traslado de Lanz, ya que algunas circunstancias lo mostraban como su reemplazante. El comisionado nunca recibió explicaciones, por lo que se conoce, sobre el interrumpido cometido del matemático en Buenos Aires, cuya contratación y traslado había sido su obra personal en beneficio del progreso científico del país.

Como es conocido, la orden de regreso no fue cumplida por Rivadavia, que prefirió permanecer en Europa para iniciar negociaciones con representantes de los gobiernos de Portugal y España.

\section{Lanz, diplomático}

De todos modos, las inclinaciones monárquicas del Directorio de Pueyrredón eran afines a las ideas de Lanz. Este guardaba, además, vinculaciones con España, donde residía por entonces parte de su familia; ello induce a conjeturar que algo más que su repulsa 
al orden imperante en Buenos Aires motivaba su regreso a Europa, donde los comisionados porteños bregaban por una salida monárquica con la instalación de un príncipe europeo.

Las circunstancias lo habían convertido en la persona apropiada para obrar de componedor o intermediario entre lo gobiernos del Río de la Plata y el de España. No obstante, tanto Rivadavia como poco después el ministro de Estado español, José García de León y Pizarro, expresaron su desconfianza y recelos hacia él; ambos sospecharon que era un agente del contrario.

Lanz había viajado desde Buenos Aires en compañía de Antonio José Valdés, que acababa de dejar la redacción de El Censor para cumplir una misión oficial ante los países de la Santa Alianza, encargada por Pueyrredón; ${ }^{29}$ el barco que los condujo partió en febrero de 1817, y Rivadavia fue enterado para que aguardara el arribo de ambos en Francia.

El destino de los dos hombres, unidos en el largo viaje transatlántico, presenta sugestivas analogías. Subvencionados por el gobierno nacional, uno ciertamente para cumplir una misión política y el otro aparentemente para fomentar el progreso científico - debía procurar en Europa elementos para perfeccionar el cometido de la Academia - , quedaron emparentados finalmente al presentarse ante las autoridades españolas con intenciones amistosas; el primero fue redactor de manifiestos para disuadir a los revolucionarios y ganar una opinión favorable a la reconquista entre las potencias europeas; el segundo actuó como informante de la situación en Buenos Aires ante las autoridades peninsulares, y fue autor de un plan para llegar a la reconciliación con el gobierno porteño, como veremos luego. ${ }^{30}$

29 Del director supremo al emperador de Austria. Enero de 1817. De Antonio Valdés al director supremo. Buenos Aires, 29 de enero de 1817. En C.B.R., tomo II, págs. 323-327 y 332. Apéndice Documental, doc. 3 y 5 .

30 El Director Supremo era afecto a emplear oscuros y peligrosos emisarios en sus asuntos diplomáticos», ha comentado Molinari: Fernando VlI y la emancipación.... pág. 285, nota. Entre ellos, cabría citar también a Juan José D'Escouber, un francés que fue comisionado por Pueyrredón para que estableciera contactos con el gobierno francés, y que en efecto inició gestiones para formalizar intercambios comerciales. Vid Piccirilli, R.: Un precursor de la diplomacia..., 
Si bien no se conoce si se dedicó efectivamente a su labor científica en París, lo cierto es que Lanz no cumplió de inmediato con su presentación ante Rivadavia, quien no ocultó las sospechas sobre su conducta. Su disgusto había aumentado al tener que atender con un subsidio mensual, extraído de sus cortos recursos, a una cuñada del matemático; ${ }^{31}$ el disgusto se convirtió en amargura cuando comprobó el incumplimiento de Lanz. En junio de 1817 expresó a Belgrano el desagrado que le había causado la «resolución» del matemático, refiriéndose seguramente al abandono de la dirección de la Academia. ${ }^{32}$

Esta situación quedó superada cuando Lanz se presentó, por fin, al domicilio de Rivadavia, le entregó el duplicado de la orden de regreso y le informó sobre la misión secreta que traía Valdés. ${ }^{3 .}$ A partir de entonces las manifiestas sospechas desaparecieron, pues mantuvo contactos amistosos con él, no obstante haber entrado Lanz ya en comunicación con el Embajador español. Todas las reservas se concentraron entonces en el compañero de viaje, Valdés, cuya actividad al servicio de España fue pública y notoria desde $1818 .{ }^{34}$

Una prueba de la estima que Rivadavia le siguió profesando puede encontrarse en la designación de Lanz como miembro correspondiente en París de la Sociedıd Literaria de Buenos Aires, promovida por el primero cuando se desempeñó como ministro del gobierno argentino, en $1822 .{ }^{35}$

Valdés fue el primero en aproximarse al representante español en París, conde de Fernán Núñez; y fue también quien introdujo en la embajada a Lanz, auspiciado por un amigo común, el general español Miguel Ricardo de Alava, un liberal que había capeado la

31 De Rivadavia a Pueyrredón. París, 26 de diciembre de 1816. Vid nota 26.

32 De Rivadavia a Belgrano. París, 6 de junio de 1817. En C.B.R., tomo l, págs. 228-231, doc. 80 .

33 De Rivadavia a Pueyrredón. París, 30 de junio de 1817. En C.B.R., tomo I, págs. 231-233, doc. 81 .

34 De Rivadavia a Pueyrredón. Paris, 15 de febrero de 1818. Del secretario de Gobierno de Buenos Aires a Rivadavia. Buenos Aires, 31 de julio de 1818. En C.B.R., tomo I, págs. 280-282 y 298-299, doc. 87 y 94 . pág. 59 .

35 Vid Piccirilli, Ricardo: Rivadavia y su tiempo. Buenos Aires, 1960, tomo II, 
persecución absolutista y era entonces embajador ante los Países Bajos.

Valdés comenzó por referir a Fernán Núñez que su presentado había recibido correspondencia de Buenos Aires, la que daba cuenta de una conspiración para derrocar al director; al ser descubierta, había desencadenado la deposición de miembros del gobierno y su reemplazo por elementos adictos a España; le aseguró que conocía a los nuevos gobernantes y sabía de sus inclinaciones para llegar de cualquier forma a un arreglo con Fernando VII.

Aunque es cierto que Pueyrredón se enfrentaba con una firme oposición, es fácil advertir que Valdés magnificaba y aun deformaba los hechos; el propósito debió ser el de aparecer ante el gobierno español como una pieza importante de un futuro acuerdo. Llegó al extremo de lamentarse ante el embajador por no estar autorizado por el rey para hacer saber a sus amigos de Buenos Aires el partido que él había tomado y no poder, por tanto, iniciar de inmediato las gestiones conciliatorias; afirmó a Fernán Núñez que no dudaba en atraer a esos amigos cuando pudiera expresar con sinceridad y amplitud las razones que expondría en favor de la causa.

Fernán Núñez comunicó estas revelaciones al ministro Pizarro, manifestando su opinión de que era inútil mantener a Valdés en París sin destino ni aprovechamiento; ${ }^{36}$ además, sintió interés $\mathrm{y}$ curiosidad por conocer a Lanz, aprovechándose entonces del gener.ll Alava, a la sazón en París, quien participó en la entrevista sostenida por el embajador y el matemático, en el mes de septiembre.

\section{El plan de pacificación}

En la entrevista Lanz expuso que la mayoría de los hombres sensatos de Buenos Aires sólo deseaba la tranquilidad y el restablecimiento de autoridades legítimas; agregó que las continuas mudanzas de los gobiernos habían provocado cansancio y fastidio, ruina y desolación. Le dijo asimismo que aún gozaba allí de un

36 Archivo General de Indias. (En adelante, A.G.I., Estado, 99, doc. 140. De Fernán Núñez a José Pizarro. París, 9 de agosto de 1817. 
sueldo suficiente, pero que había preferido abandonar el país, y augurado que poco a poco éste quedaría despoblado si persistía la caótica situación; dijo también estar convencido que si los gobiernos no se atrevían a exponer a la metrópoli sus deseos de reconciliación era porque se consideraban juzgados en la causa y temían no obtener el perdón del rey.

Expresó a continuación que lo más adecuado era enviar una corta fuerza a Buenos Aires, cuyo jefe debía ofrecer garantías de moderación y prudencia, y asegurar un olvido amplio y general junto con proposiciones ventajosas de comercio; de este modo España contaría, a su juicio, con la colonia más fiel. Se mostró dispuesto también a participar en la tarea y terminó prometiendo una memoria escrita explayando sus ideas.

El conde acogió con beneplácito la exposición, pues estaba convencido que sólo serían eficaces los medios conciliatorios; no ocultó a Pizarro el agrado que sentía al realizar este provechoso contacto. ${ }^{37}$

Lanz cumplió de inmediato con su promesa de presentar un escrito; ${ }^{38}$ en él dijo que, no obstante las luchas internas que las devoraban, los gobernantes de las Provincias Unidas estaban dispuestos a no ceder en las conquistas de libertad de comercio y de industria, y que para mantenerlas se entregarían a cualquier potencia que se las garantizase. Afirmó que, aunque todos coincidían en estos fines últimos, las opiniones en Buenos Aires se encontraban divididas entre republicanos, federalistas, realistas, realistas constitucionales, etc. Estimó que los adictos a Portugal eran numerosos y poderosos, pero más aún lo eran los partidarios de España y a este partido se inclinarían los primeros si se disipara el temor a la venganza.

Una buena manera de restablecer la confianza sería la designación de jefes políticos y militares honrados y prudentes $\mathrm{y}$, obviamente, la libertad de comercio y de industria, tan beneficiosa para América como para España. Tan dispuestos consideraba a los diri.

37 A.G.I., Estado, 99. De Fernán Núñez a José Pizarro. París, 12 de septiembre de 1817 .

38 A.G.I., Estado, 99, doc. 152. De Lanz a Fernán Núñez. París, 12 de septiembre de 1817 .

Tomo XI.VII 
gentes rioplatenses que proponía el envío de una fuerza armada con el sólo propósito de asegurar el orden público; temía que individuos sin escrúpulos aprovecharan la ocasión para conspirar contra el gobierno enrostrándole su actitud amistosa hacia la metrópoli.

Afirmó también la necesidad de respetar a los extranjeros raldicados en el Río de la Plata, y en especial los capitales y mercaderías de sus comerciantes, como así también los grados alcanzados por aquellos que se habían incorporado a los ejércitos revolucionarios. Debería mantenerse la legislación dictada en favor de los esclavos.

En cuanto al medio de llevar a cabo la aproximación, estaba convencido que lo más adecuado era contar con la mediación de alguna potencia, que sirviera de apoyo y garantía para el cumplimiento de los contratos que se celebrasen.

Estas informaciones y juicios fueron transmitidos a Madrid, donde Pizarro centralizaba la dirección de la reconquista desde el Ministerio de Estado. Antes de adoptar actitud alguna al respecto, y luego de informar de todo a Fernando VII, el ministro quiso enterarse de la identidad de este nuevo colaborador; ofició a su colega de Guerra pidiéndole información, pero en los archivos de esa Secretaría no fueron encontrados antecedentes de la trayectoria militar de Lanz al servicio del rey. ${ }^{39}$

En definitiva, el plan fue a parar al grueso expediente de pacificación, donde - junto con otros papeles similares - sirvió para ilustrar a los gobernantes españoles su política ultramarina. ${ }^{40}$

Las ideas desarrolladas por Lanz no deben considerarse extemporáneas, si se tienen en cuenta las circunstancias políticas en que se debatían las Provincias Unidas por entonces. Al margen de si

39 A.G.I., Estado, 99. De José Pizarro al secretario de Guerra. Palacio, 25 de septiembre de 1817. De José Pizarro a Fernán Núñez. Madrid, 25 de septiembre de 1817. De Francisco de Eguía al secretario del despacho de Estado. Palacio. 26 de octubre de 1817.

40 Entre ellos, el plan que presentó en esos mismos meses Manuel Moreno desde Baltimore. basado en la incorporación de las Provincias Unidas a la Corona española. Vid Heredia, Edmundo A.: Manuel Moreno al servicio de la Corona española, en 1817. En «Nuestra Historia», núm. 8, Año III, págs. 67-83. Buenos Aires. 1970; y Piccirilli. Ricardo: Manuel Moreno, el expatriado de Baltimore. En *Universidad», núm. 66. Santa Fe, octubre-diciembre de 1965, y en «La Nación». Buenos Aires, 29 de noviembre de 1964. 
pudo ser o no un agente del gobierno porteño, sus expresiones ante el embajador español traducían por lo menos una parte del pensamiento del Directorio; que no trabajaba en su contra lo muestra la falsa afirmación según la cual Pueyrredón se había rodeado de personas adictas a España, con lo que intentaba crear ante el monarca una imagen benigna del director; además, sostenía la necesidad de conservar una de las ambiciones capitales de los dirigentes porteños, esto es la libertad de comercio. El envío de una fuerza española que resguardara a las autoridades contra los enemigos de la conciliación, marcaba el interés por eliminar a los caudillos federalistas de las provincias, que bajo el patronazgo de Artigas hacían peligrar la estabilidad del gobierno centralista porteño.

Por último, la mediación de una potencia extranjera -y esto no era necesario nombrar a Gran Bretaña para entender que a ella se refería Lanz - aseguraba respeto a las condiciones básicas que sostenían los porteños, puesto que éstas coincidían en buena parte con los intereses de la mediadora.

Por lo menos hasta aquí los gobernantes de Buenos Aires, en su fuero íntimo no hubieran podido tacharlo de traidor; pero es claro que la parte más delicada y trascendental era el retorno a la dependencia política de España, y éste es un aspecto en el que Lanz hizo gala de sutil diplomacia. En su presentación escrita no entró a tratar en manera alguna de independencia o de dependencia, ni adelantó concepto sobre la forma del futuro gobierno de Buenos Aires; usó reiteradamente del término «reconciliación», lo que indudablemente no implica sumisión. $Y$ en cuanto a los arreglos, debían hacerse bajo la forma de contratos, con lo que pretendía implícitamente el reconocimiento de la existencia de entidades autónomas y responsables.

Es cierto que hablaba de «colonias» y de «metrópolis», pero es obvio que usaba una denominación común por entonces y referida a una situación secular, por lo que ello no significaba una toma de posición con sentido prospectivo. Insistió en que no correspondía indulto ni amnistía, sino un olvido total de lo pasado; en efecto, lo primero implicaba el perdón de la autoridad hacia el súbdito descarriado, y no eran esos los principios que Lanz enarbolaba. 
En resumen, lejos estaba de preconizar una vuelta a la situación anterior a 1810 , sino por el contrario intentaba cimentar e institucionalizar los principios económicos alentados y establecidos por el gobierno de Buenos Aires; al mismo tiempo se desembarazaba el Directorio de los problemas que provocaba la acción de los caudillos provinciales.

Bien pudo ser una avanzada de la estrategia rioplatense diversificada en sus tentativas internacionales en un rosario de posibilidades que Rivadavia desplegaba denodadamente por entonces en las Cortes europeas. Ante el fracaso de sus gestiones directas en la: Corte madrileña, ésta pudo ser una prolongación de aquélla o una variante en los intentos de aplazar la firme vocación armamentista española para destruir la revolución americana.

Quizá el gobierno de Buenos Aires entendió que las erogaciones que habían demandado los sueldos y el traslado de Lanz podían tener una más directa e inmediata utilidad que la del fomento de las ciencias. De todos modos, el plan presentado fue enviado al archivo por el ministro de Estado español, aunque bien pudo ser un documento de consulta para los proyectos de pacificición. Pizarro daba culminación por entonces a un plan global de reconquista en el que no cabían gestiones directas y particulares de los gobiernos revolucionarios o de sus oficiosos delegados. Atento a la situación internacional, Pizarro se propone llevar adelante un pragmático programa que intentaba compatibilizar las expediciones armadas con las mediaciones de las potencias europeas. Las ostentaciones de fuerza servirían - según las especulaciones del ministro- para obtener mejores condiciones en las mediaciones, y éstas permitirían acercarse a los revolucionarios $y$ llegar a una transacción ventajosa en las difíciles circunstancias. El punto undécimo de su plan, precisamente, decía que «la mediación sólo debe dirigirse a los puntos que nos son inaccesibles, Buenos Aires y Caracas». ${ }^{41}$ Es decir que, como no era posible envi.rr fuerzas militares eficientes sobre Buenos Aires y Caracas, se recurriría allí a la intervención mediadora de las potencias.

41 Vid Heredia, Edmundo A.: Planes españoles para reconquistar Hispanoamérica 1810-1818. Buenos Aires, 1975. 
Pizarro consagró su atención en todo ese año 1817 a perfeccionar e introducir su plan en el Consejo de Estado, y esto explica que no diera mayor cabida a tentativas parciales como la que Lanz propuso por intermedio del embajador en Francia.

\section{LA ETAPA COLOMBIANA}

\section{Francisco Antonio Zea en Europa}

Debemos sobrepasar un interregno de varios años para encontrar la segunda vinculación de Lanz con la América hispana. En ese lapso, el mundo de los hombres de ciencia vinculados a América aparecía ligado con los movimientos revolucionarios y los proyectos de introducir los estudios científicos en las nuevas naciones. En los salones y gabinetes europeos que ellos frecuentaban, alternábanse los planes diplomáticos y revolucionarios con los de los empresarios, mercenarios y banqueros. Pero a ellos se agregaban con su propia gravitación los de los artistas y los científicos, muchos de ellos también románticos y aventureros, que veían en estos encuentros la posibilidad de lanzarse a las tierras y mares americanos en sus afanes de exploración y de estudio, compatibles con los de la explotación de las riquezas ultramarinas y la colaboración con la gesta libertaria.

Fue en ese ambiente cosmopolita y controvertido, que se mecía entre los extremos de la utopía y de la realidad, del idealisno y del utilitarismo, donde cumplió su misión diplomática Francisco Antonio Zea, enviado por el gobierno de la Gran Colombia ante las Cortes europeas. Zea era el vicepresidente de la federación Grancolombiana, en la que entonces sentaba su indiscutible jefatura cl general Simón Bolívar. Conservando de manera simbólica la segunda magistratura - y disimulando así el carácter superfluo de un cargo que era incompatible con la autoridad absoluta del Libertador-, Zea partió en marzo de 1820 como enviado extraordinario y ministro plenipotenciario. Tan pronto se estableció en Francia entró en contacto con aquel complejo mundo. 
Debió ser muy grato para él reencontrarse con un grupo de hombres de ciencia que había frecuentado durante su larga estancia anterior en Europa, cuando fuera desterrado por sus ideas independentistas. En rigor, Zea se inclinaba más a la ciencia que a la política, y se había destacado en el estudio de las humanidades y de las ciencias naturales. En aquella primera residencia europea había sido director del Jardín Botánico de Madrid, pero debió salir de España por su afección al régimen napoleónico. En Francia y en Inglaterra tuvo entonces la oportunidad de alternar con los naturalistas Fréderic y Georges Cuvier, el viajero y naturalista Aimé Bonpland, el matemático, físico y astrónomo Dominique Arago, el naturalista Jean Audouin, el naturalista, explorador y militar Jean Baptiste de Saint Vincent, y el mineralogista, geólogo y ceramista Alexandre Brongniart. También conocería entonces al barón Alejandro de Humboldt y por su intermedio a nuestro José de Lanz.

Regresado a su patria en 1815 , cinco años después se reencontraba con aquel mundo europeo y estaba en condiciones de of recer a sus amigos científicos una oportunidad para proseguir sus estudios en tierras americanas. ${ }^{42}$

En tanto, Zea fue desgraciado en el cumplimiento de su misión principal, que consistía en obtener empréstitos con la hipoteca de tierras fiscales, minas y propiedades colombianas. Su gobierno terminó por perder toda la confianza depositada en él, advertido por las denuncias que le hicieron llegar posteriores comisionados que revisaron las negociaciones iniciadas o continuadas por el enviado extraordinario con banqueros europeos. Lo cierto es que Zea encontró a su arribo desconfianza y descrédito hacia el gobierno colombiano, a raíz de anteriores operaciones, y se vio envuelto en problemas derivados del incumplimiento de deudas ya contraídas. Sus antecesores habían ido a la cárcel por insolventes e incumpli-

$42 \mathrm{El}$ reencuentro no se produciría con Bonpland, quien en 1817 se habia trasladado a Buenos Aires, y en noviembre de 1821 iniciaria su largo cautiverio en Paraguay. La situación del sabio provocó enérgica reacción de su amigo Simón Bolivar, quien llegó a proyectar una expedición por él dirigida para liberarlo y escarmentar al dictador Francia. 
dores. Uno de aquellos comisionados, Fernando Peñalver, había intentado sin éxito asociarse con diputados de Chile y de Buenos Aires para hacer una causa común en las solicitudes de reconocimiento de la independencia, de empréstitos y de provisión de armas. Véanse entonces qué mal se daban los pasos encaminados a entablar la solidaridad entre los movimientos revolucionarios hispanoamericanos. Una de las gestiones de los emisarios colombianos, conocida como el «negocio Mackintosh», terminó en escándalo público por tratarse de una venta de armas inservibles. Zea, inexperto en cuestiones comerciales y financieras, se debatía en medio de estos turbios manejos en los cuales quedó fatalmente complicado. En tanto, su mujer y su hija fueron acogidas en el hogar de los Bonpland, en París.

El día que se estudien en forma conjunta estas espinosas gestiones de los enviados hispanoamericanos, que se establezcan las vinculaciones entre ellos, y se formulen comparaciones entre los cometidos de los representantes de cada una de estas naciones, tendremos una representación más veraz y ajustada de esta difícil etapa de la formación de las nacionalidades hispanoamericanas.

Zea se dio tiempo para mantener aproximaciones con el embajador español en Londres, duque de Frías, a quien le entregó un proyecto de confederación hispanoamericana. ${ }^{43}$ Es curioso que, en tanto el presidente colombiano avanzaba en su idea de una gran federación americana que conduciría a la realización del Congreso de Panamá, en el que el principio fundamental era concertar la acción contra los intentos reconquistadores de la metrópoli, el alicaído vicepresidente se acercaba a España con este proyecto de confederación que incluía un acuerdo con ésta, sobre la base de un cuerpo político que armonizase los intereses del antiguo amo con la vocación emancipadora de las nuevas naciones. En él proponía el reconocimiento de la independencia, mutua defensa y ayuda, la libre introducción de productos en América, libertad en la clección

43 Vid Jos, Emiliano: Una sociedad hispánica de naciones en 1820 según el plan de Francisco Antonio Zea. En Contribuciones para el estudio de la historia de América. Homenaje al Dr. Emiliano Ravignani. Buenos Aires, 1941. 
de la ciudadanía y la formación de una Comisión de indemnizaciones por los daños causados durante la guerra.

Aunque el proyecto, presentado en octubre de 1820, ya había sido desestimado antes de terminar ese año, el acercamiento al duque de Frías le valió la autorización del gobierno español para trasladarse a Madrid y entrevistarse allí con sus autoridades.

Estas referencias, ya reproducidas en la historiografía venezolana y colombiana, son traídas aquí para remarcar algunas semejanzas con los pasos seguidos años antes por Bernardino Rivadavia, semejanzas que se acentuarían al repetir Zea la experiencia rivadaviana de contratar a Lanz para el progreso científico de su país. Así como el argentino había llegado en mal momento a Madrid, a fines de 1816, debido a la reacción que provocó la decisión independentista del Congreso de Tucumán, ahora Zea se encontró con similar situación al arribar a la capital española cuando el gobierno tomaba noticias de la ruptura del armisticio firmado por Bolívar y Morillo. Como consecuencia de aquel armisticio, emisarios colombianos habían llegado poco antes a la península, y habían fracasado ya en sus gestiones de reconocimiento cuando Zea hizo su entrada en Madrid. Pronto sufrió el desaire de la expulsión, decidida por el gobierno español ante la reanudación de la guerra y la presión de la opinión pública.

El diplomático se dirigió de allí a París, donde dedicó buena parte de su tiempo a cumplir con una de sus instrucciones, cual era la de seleccionar y contratar «un grupo de jóvenes profesores sobresalientes en distintas especialidades de las ciencias, las artes y las industrias, para enviarlos a Colombia a enseñar sobre el terreno sus vastos conocimientos». ${ }^{44}$ Los hermanos Cuvier y Humboldt colaboraron en esta tarea, y el sabio alemán le recomendó a Lanz. Con el asesoramiento de los nombrados y la ayuda de un joven peruano - Mariano de Rivera, alumno de la Escuela de Minas de París-, elaboró Zea un vasto plan de contratación de científicos con el propósito de fundar en Bogotá un establecimiento destinado a formar ingenieros civiles y militares. El químico y agrónomo

44 Botero Saldarriaga, Roberto: Francisco Antonio Zea. Bogotá, 1970. 
Jean Baptiste Boussingault se haría cargo de las cátedras de Química y Mineralogía, ${ }^{45}$ Rivero se desempeñaría como su ayudante en la organización de un gabinete de Mineralogía. ${ }^{46}$ Roulin enseñaría Anatomía y Fisiología. Goudet formaría colecciones geológicas. Por último, Carlos Cazar de Molina instalaría una sala de dibujo y litografía.

\section{El contrato entre Zea y Lanz}

Como resultado de estos contactos y gestiones, Zea suscribió finalmente con Lanz un contrato para contar con sus servicios en Colombia. ${ }^{47}$ Zea firmó el documento en su carácter de vicepresidente de la República de Colombia y su ministro plenipotenciario, y en uso de los poderes «ilimitados» que declaraba tener. Por él Lanz se comprometía a entrar al servicio de la República como ingeniero geógrafo, a elaborar las cartas geográficas del país y a formar un cuerpo de especialistas en ese ramo, del que sería director perpetuo. Se comprometía a prestar servicios propios de su conocimiento en la Marina, y de programar la creación y funcionamiento de un establecimiento de enseñanza si así le fuese requerido. Por su parte, la República le confería el grado de coronel en servicio activo con un sueldo de mil pesos fuertes anuales, y la gratificación de media paga cuando se hallase en expedición geográfica. La mitad de ese sueldo sería pagada en París a la esposa del científico, pues esta vez no había querido repetir la experiencia porteña, y se quedaría en Francia. El gobierno se hacía cargo del traslado y de la compra de los instrumentos que Lanz indicara como necesarios.

45 En efecto, Boussingault pasó a la Gran Colombia. donde quedaría encargado de la explotación de minas entonces abandonadas. Recorrí́ Venezuela por el Orinoco, se trasladó a Ecuador y Perú y escaló al Chimborazo. Acompañó también a Bolívar en algunas de sus campañas militares.

46 Rivero cumpliría luego una importante labor cientifica en su patria. Entre otras actividades fundó en Perú la revista «emorial de Ciencias Naturales» y dirigió el Museo de Historia Natural y de Antigúedades. Llevó a cabo también misiones diplomáticas en Europa.

47 Fue firmado en París, el 21 de mayo de 1821 . Hemos encontrado un ejem. plar de los originales en el Archivo Nacional de Colombia. (Én adelante, A.N.C.), Colección Ortega Ricaurte, Caja 220. 
Varios meses transcurrieron en los preparativos del viaje. A comienzos de noviembre los contratantes daban las últimas puntadas a la empresa que se iniciaba, y Lanz recibía un anticipo de setecientos francos a cuenta de sus sueldos. ${ }^{48}$ Partió al fin de El Havre en los últimos días de noviembre, acompañado de un joven matemático, Agustín Leperiere, a quien Zea le había conferido el grado de subteniente de Ingenieros; ${ }^{49}$ Zea se había preocupado para que fuera provisto «de todos los efectos e instrumentos que ha pedido, y que se han fabricado bajo su inspección por los más célebres artistas. ${ }^{50}$ En tanto, él seguía cuidando que fuesen entregados otros instrumentos, que enviaría luego a Colombia.

El viaje del científico fue revestido de profunda expectativa. Estaban presentes en la mente de la comunidad intelectual a que pertenecía las expediciones de fines del siglo anterior, que habían recogido importantes elementos útiles para enriquecer los conocimientos de las ciencias naturales. Los consejos y la sugestión de Alejandro Humboldt, el mayor de esa pléyade de intelectuales, y el recuerdo de su venturosa experiencia americana, obraban allí a manera de estímulo. La empresa que iniciaba Lanz era considerada

48 A.N.C., Colección Ortega Ricaurte, Caja 220. Recibo firmado por Lanz. París, 7 de noviembre de 1821 .

49 Así lo informa José Tiburcio Echeverría al ministro de Relaciones Exteriores de Colombia. París, 20 de noviembre de 1821. En La misión diplomática de Revenga y Echeverria: Borradores de la correspondencia de Echeverría con el Ministro de Relaciones Exteriores de la Gran Colombia. «Boletín de la Academia Nacional de la Historia», tomo XX, núm. 78. Caracas, abril-junio de 1937.

50 A.N.C., República, Guerra y Marina, tomo 18, segunda parte, fol. 253. La transcripción de su detalle puede ser útil para quienes se interesan por los equipos cientiffcos que llegaban a América en ese época:

*Lista de los objetos que lleva el señor Lanz, para la espedición geográflca.

Un teodolite de Gambey, repitiendo los ángulos horizontales y verticales. de diez pulgadas de diámetro ambos círculos.

Una aguja de declinación por el mismo artista.

Dos barómetros por Sortin.

Un metro en cobre por el mismo.

Un anteojo astronómico por Cochoix.

Un buen estuche de matemáticas por Rochette.

Un cronómetro de Brequet-n 1537.

Un cajón que contiene todo lo necesario para formar un pequeño bureau de confecsión de cartas, como son papel de varias clases para trazar dichas cartas.

Tres cajoncitos de pintura, colección de lápices, pinceles, reglas, escua. dras, etc.». 
como una verdadera expedición aventurada a regiones aún ignotas. A ello se agregaba el aire de libertad y emancipación que enmarcaba y formaba un ambiente idealista y romántico a la misión científica. Antes, los expedicionarios eran viajeros que debían pedir permiso, sortear o hasta enfrentar a veces las actitudes poco hospitalarias y desconfiadas de las autoridades coloniales; ahora, en cambio, eran llamados, condecorados e incorporados al servicio de los gobiernos revolucionarios, y recibían la promesa de ayuda y apoyo para la realización de sus campañas y viajes a través de aquellos territorios ganados para la vida en libertad.

Zea vivía ese entusiasmo con alborozo y orgullo personales, porque se sentía promotor de una empresa tan elevada, y así le escribía a su gobierno:

“Es increíble el entusiasmo que ha ecsitado entre los sabios esta espedición, por la cual presagian lo mucho que las ciencias y la civilización deben esperar de nuestra independencia. Los ilustres amigos de nuestra causa han celebrado sobre manera que demos esta prueba a la Europa de que bien lejos de ser unos bárbaros incapaces de gobernarse, como los Españoles y sus partidarios se han empecinado en persuadirlo, conocemos el precio y mérito de las luces y nos apresuramos a contribuir por nuestra parte a los progresos del talento humano. El célebre Barón de Humboldt, en quien se reúnen ambos títulos de sabio y ciudadano ha tomado tanto interés en la empresa, que a pesar de sus grandes ocupaciones, ha tenido largas y repetidas conferencias con el Sr. Ianz para darle noticias que han de serle muy útiles, y llamar su aten. ción sobre los objetos que cree más importantes»). ${ }^{51}$

Como se ve, Lanz aparecía presentado ante el gobierno colombiano con el aval de Humboldt, lo que de por sí era ya suficiente garantía de sus méritos. Además, sabría por información de Zea que era un «ilustre americano antiguo amigo de la libertad». Según

51 A.N.C., República, Guerra y Marina, tomo 18, segunda parte, fol. 225. De Zea al ministro de Relaciones Exteriores de Colombia. París, 14 de noviembre de 1821 . 
los datos transmitidos por el diplomático, había estado al servicio de la Marina española, y había ocupado luego una cátedra de Matemáticas en París. Más tarde, había sido ingeniero de puentes y calzadas en España, ocasión en que alcanzó el grado de comisario ordenador con el encargo de dirigir una escuela de Ingenieros. Bajo el gobierno de José Bonaparte había sido director del Depósito Hidrográfico y jefe de División en el ministerio del Interior; finalmente, había sido prefecto de la Córdoba andaluza. En rigor, estos datos de su vida pública no han sido confirmados en las posteriores referencias bibliográficas y documentales sobre el científico. Zea sabía también que Lanz había estado en Buenos Aires, adonde fue para «consagrar sus luces y su zelo a la causa de la independencia, pero disgustado por la lucha de los partidos, y del desorden que allí encontró, regresó a Francia, y su vuelta, completó el descrédito de aquel desgraciado país». Los elogios que Zea prodigó en su presentación al gobierno colombiano ponían en relieve la diferencial de trato que obtendría en su nuevo destino con respecto al que recibiera en Buenos Aires, pues los colombianos, decía, «sabremos apreciar mejor a un sabio, que por sus grandes conocimientos, por su laboriosidad, por su patriotismo, por una actividad incomparable, y por sus ecselentes cualidades, debe considerarse como la adquisición más preciosa que puede hacer la República».

Penoso sería, para Lanz, que la persona que lo contratabal y así lo recomendaba había entrado ya en el mayor descrédito ante el gobierno colombiano, como resultado de sus desgraciadas transacciones financieras. Esto empañaba seriamente el camino que comenzaba a transitar el científico hacia aquellas tierras americanas, y estorbaba la limpieza y brillo de sus antecedentes y de la que debió ser consagratoria recomendación de Humboldt.

\section{Lanz en la Gran Colombia}

Lanz y su acompañante Leperiere concluyeron el viaje transoceánico en San Thomás, y de allí se dirigieron al continente. En febrero de 1822 estaban en Valencia, desde donde el general Carlos Soublette hizo las diligencias para que continuaran su camino 
hacia el destino final, la ciudad de Bogotá. ${ }^{52}$ En marzo estaban en Caracas, y allí Lanz solicitó, el 8 de ese mes, los auxilios necesarios para seguir a la capital colombiana. ${ }^{53} \mathrm{El}$ camino comenzaba a erizarse por obra de una burocracia quizá deliberadamente poco preparada a beneficiar al científico; en efecto, el intendente había dispuesto que Lanz debía pedir esos auxilios para que la solicitud fuese puesta a consideración de las autoridades, en una muestra de su intención de revisar las amplias facilidades comprometidas por Zea en París.

El intendente se tomó su tiempo para decidir el destino de Lanz; resolvió que era mejor que permaneciera por un tiempo en Caracas - no sabemos por qué razones- y que el sueldo acordado era demasiado generoso, por lo que lo redujo a una cifra muy inferior. Así se lo comunicó a Lanz el 27 de marzo, en nota que éste recibió once días después, a pesar de que remitente y destinatario residían en la misma ciudad. Esto significaba un cambio fundamental con respecto a lo acordado con Zea, y a las promesas que éste le formulara en París. La reducción del salario, por lo demás, permitía vaticinar una general revisión de todo lo acordado.

La resolución de la autoridad venezolana cayó sobre Lanz como un balde de agua fría, aunque ya había tenido oportunidad de observar que la situación no se presentaba como se la había pintado Zea. Seguramente ya venía acumulando desencanto desde que pisó tierra venezolana y debió iniciar y sostener gestiones para su desplazamiento por el interior del territorio, en lugar de encontrar su camino alfombrado como lo hacía presumir el generoso contrato.

Lanz respondió a Soublette que no estaba dispuesto a admitir ningún cambio en las estipulaciones firmadas en París, ỳ le negó su derecho a modificarlas unilateralmente. Se quejó por la disminución de la paga, dijo no tener dinero y que, si debía esperar más de

52 Archivo General de la Nación de Venezuela. (En adelante, A.G.N.V.), Intendencia de Venezuela, tomo LXXIII, fol. 163. De Soublette al intendente interino del Departamento. Cuartel General de Valencia, 28 de febrero de 1822.

53 A.G.N.V.. Intendencia de Venezuela, tomo LXXV, fol. 210. De Andrés Narvantes al general intendente del departamento de Venezuela. Caracas, 1' de marzo de 1822. 
un mes para recibir el próximo sueldo, quedaría reducido «a vivir de pan y agua o a vender mis libros y efectos». ${ }^{54}$ Con firme resolución, exigió el cumplimiento del contrato, o bien «para evitar nuevos gastos y trastornos, lo dé por nulo, y me acuerde la gratificación, por pequeña que sea para que yo pueda regresar a París, mientras las circunstancias permiten a la República realizar sus grandes planes de instrucción pública». Terminó diciendo que era esto último lo que deseaba, pues su salud comenzaba a quebrantarse.

A Lanz se le presentaba una situación más desagradable que la que había soportado en Buenos Aires; en Colombia sólo había comenzado su cometido, y ya la actitud del gobierno y la situación encontrada le hacían desistir de la empresa.

¿Cuál era el motivo por el que Soublette decidió dar trato tan menoscabado al científico? La respuesta general debe ser comprendida en el aún conflictivo cuadro de la guerra de Venezuela y de la Nueva Granada contra los realistas. Aunque en junio de 1821 se había obtenido el decisivo triunfo militar en Carabobo, aún los esfuerzos de los revolucionarios estaban concentrados en la expulsión de los restos del poder militar español, que se mantendría atrincherado durante más de dos años todavía en la fortaleza de Puerto Cabello. El triunfo debía aún extenderse, y a ese plan se entregaron Bolívar y sus seguidores luego de Carabobo, en una formidable marcha que tendría su punto final en la ciudad altoperuana de Potosí. También era necesario consolidar la federación Grancolombiana, superando los conflictos internos que sostenían las fracciones locales. No era tiempo aún para el fomento de las ciencias. La mente de Soublette, como la de otros generales que comandaban las campañas militares, estaban programadas en un estricto plan castrense de asegurar el dominio de los territorios y exterminar todo vestigio de fuerzas militares españolas. La llegada de un científico, con sus instrumentos, sus láminas y sus proyectos de exploraciones geográficas eran, en esas circunstancias, un estorbo para las reconcentradas miras del general.

54 A.G.N.V., Intendencia de Venezuela, tomo VII, fols. 164 y 165 . De Lanz al general intendente Carlos Soublette. Caracas, 8 de abril de 1822. 
Las estrecheces a que estaba reducido el erario por la prolongada situación bélica $\mathrm{y}$, las penurias que las tropas debían soportar en las fragorosas campañas, debieron repercutir también para que se considerara hasta como un dispendio suntuoso el conceder a Lanz y a su acompañante sueldos mayores que los que recibían los oficiales de igual grado que los conferidos a los viajeros. Quizá por eso Soublette se refirió a Lanz en su correspondencia sólo como un «oficial», tratando de sujetarlo a condiciones iguales a las que tenían los que integraban los cuadros del ejército colombiano.

Por lo demás, ¿quién enviaba a Lanz en condiciones tan favorables? Era aquel que, a juicio de las autoridades grancolombianas, había malversado los fondos de la República y había expuesto irresponsablemente las riquezas naturales de su suelo y de su subsuelo. La actividad de Zea en Europa era entonces revisada con ojo crítico y hasta suspicaz en sus menores detalles, y en ella estaba involucrada la contratación de Lanz.

Con todo, pudo más el peso de los compromisos contraídos y, seguramente, el conocimiento personal que entablaron Soublette y el matemático, en el cual éste debió conquistar la confianza del general e inspirarle respeto y consideración. También Lanz había suscitado, al comienzo de su estancia en Buenos Aires, los recelos de los miembros del Consulado, pero de inmediato se había granjeado las simpatías y el respeto de todos, seguramente por sus cualidades personales e intelectuales. Parece pertinente suponer que también ahora esas cualidades fueron más eficientes que las mismas cláusulas del contrato firmado con Zea. Así, Soublette dio órdenes para que le pagara lo que fijaba el contrato y favoreció el establecimiento de la clase de Matemáticas con arreglo a lo que aconsejera una comisión de estudios. Con esto, parecía intentar que Lanz quedase radicado en Caracas, aprovechando así para Venezuela las enseñanzas del científico.

En efecto; por lo que sabemos, Lanz permaneció un tiempo en Caracas, para luego seguir a Bogotá. Zea fue enterado de las dificultades que había tenido a su llegada, como así de la rotura de algunos de sus instrumentos, que repuso y envió con Mariano de Rivero, el joven peruano que se sumó al grupo de científicos que 
viajaron luego. Zea insistió en la necesidad de fundar en la capital un Museo de Ciencias Naturales. «Bien pronto -decía- se formarán en el Museo jóvenes que diseminándose en las provincias descubrirán los tesoros que encierran». ${ }^{55}$ Rivero recibió de Zea una importante suma para atender los gastos de la expedición que debía dirigir Lanz. La disponibilidad de estos fondos contrastaba con la escasez congénita que padecían los revolucionarios en su tierra, y el contraste no debió favorecer en nada la disposición de sus autoridades para con las actividades de Lanz en el ejercicio de su misión científica. Pero Zea entendía que las dificultades que éste había encontrado se debían a la falta de recursos del gobierno para atender sus gastos, y por ello intentó reparar esa falta con los subsidios que él le proporcionaba desde Europa. Poca gracia haría a Soublette y los suyos que Lanz recibiera tales dineros directamente, cuando ellos estaban tratando de arreglar las finanzas del país para sacarlo de la difícil situación a que lo había postrado la persistente guerra. Zea se ocupó también de atender puntualmente la parte del sueldo que debía pagar a la esposa de Lanz. ${ }^{56}$

En tanto, el ministro de Relaciones Exteriores de la Gran Colombia, Pedro Gual, intentaba poner orden en la situación de Lanz girando el contrato a la secretaría de Guerra y Marina, para que en ella se incorporara como ingeniero geógrafo. ${ }^{57}$

El historiador Mendoza, en cierta manera, apunta otras razones que pudieron gravitar en la actitud de las autoridades; cree que Zea había exagerado los méritos de Lanz, en su afán de defenderlo. Además, concluye que «no quedaron huellas muy profundas de su paso por nuestro suelo», y que sólo habría levantado un plano de la ciudad de Bogotá.

Poco más sabemos de la actividad de Lanz en territorio gran-

55 A.G.N.V., Guerra y Marina, tomo XXX, fol. 1. De Zea a Soublette. Londres, 13 de agosto de 1822.

56 Lo muestran así ocho recibos, flrmados por Thérése Bennland, por cuenta de José María Lanz, en París, y otros cinco sin firma, fechados entre diciembre de 1821 y điciembre de 1822. A.N.C., Colección Ortega Ricaurte, Caja 2̌0. Zea falleció el 28 de noviembre de 1822 , en Bath, en cuyas fuentes minerales intentaba aliviar su enfermedad, con lo que la señora de Lanz dejó de percibir su pensión.

57 A.N.C., República, Guerra y Marina, tomo 18, segunda parte, fol. 520. De Gual al secretario de Guerra y Marina. Bogotá, 15 de noviembre de 1822. 
colombiano. Sólo que se ocupó de levantar cartas geográficas de Venezuela y de Nueva Granada, las que serían publicadas en la forma de un Atlas, que constituyó el último tomo de la historia de Restrepo. ${ }^{58}$

\section{La misión diplomática c’n lirancia}

De todos modos, lo que más nos interesa aquí es seguir los pasos de la actividad diplomática de Lanz al servicio de la Gran Colombia. Al respecto, volvemos a encontrar en esta nueva etapa alguna similitud con las tareas que cumpliera unos años antes en vinculación con el gobierno de las Provincias Unidas del Río de la Plata.

Como ocurriera durante sus relaciones con el gobierno de Buenos Aires, más importancia tuvo la misión que cumpliría luego de su regreso a Europa. La causa aparente del retorno fue buscar a su esposa para reintegrarse con ella a la Gran Colombia, pero en rigor su regreso obedeció a la gestión diplomática ante el gobierno de Francia. Para ello fue provisto de una carta credencial como agente oficial ante el gobierno de Francia.

El ministro Gual le entregó también minuciosas instrucciones para el cumplimiento de su misión. ${ }^{57}$ En ellas era advertido de las

58 Restrepo, José Manuel: Historia de la revolución de la república de Colombia. Atlas. París, 1827. 13 mapas de $24 \mathrm{~cm}$., en varias escalas. Dice Restrepo en el prólogo de la obra: «Este nuevo mapa de la república de Colombia, se ha trabajado bajo la inspección del secretario del interior de la misma república (Restrepo). Fue proyectado y trazado en dos hojas de regular tamaño por el señor coronel José Lanz, matemático bien conocido, especialmente en Francia, por las obras que ha dado a luz sobre máquinas, fue continuado el mapa por varias personas inteligentes». Hemos consultado un ejemplar de la primera edición de 1827 en la Biblioteca Luis Angel Arango, de Bogotá. Con este trabajo cartográflco, Lanz puede ser reputado como un antecedente de Agustín Codazzi, considerado como el padre de los estudios geográficos en Colombia. Codazzi había estado ya en estas tierras entre 1817 y $18<2$ siendo muy joven, acompañando a temerarios corsarios en el mar Caribe y en un arrojado viaje por la región del Chocó en busca de San Martín para pedir su apoyo en la captura de Panamá. Vid Heredia, Edmundo A.: Los Estados Unidos de Buenos Aires y Chile en el Caribe. Buenos Aires, 1984., pág. 123.

Codazzi regresaría a Italia, para retornar poco después e iniciar sus estudios geográficos. No hemos encontrado conexiones entre Codazzi y Lanz, cuyas estancias en la Gran Colombia pueden haber coincidido durante un tiempo breve.

59 Reproducidas por Mendoza, Misión de José Maria Lanz. 
tensiones existentes por las maquinaciones prepotentes de la Santa Alianza, que se hacían sentir en la política europea y amenazaban extenderse a América, sólo detenidas aquí gracias a la intervención de Gran Bretaña y de los Estados Unidos. Una de las tareas encomendadas era procurar que Francia se inclinara hacia esta última actitud, a la que parecía dispuesta por la necesidad de exportar sus manufacturas. Para que ese gobierno tomara una decisión favorable, debía el agente sostener que la revolución colombiana había triunfado, y que el orden había sido impuesto. Las versiones sobre el imperio del terror en este país debían ser desvirtuadas, atribuvéndolas a la tendencia falsa de comparar la situación con los excesos producidos en Francia durante su revolución. Debía también negarse con firmeza a todo proyecto de instalar monarquías, pues este sistema no era aconsejable para pueblos nuevos y por la necesidad de oponerse al régimen impuesto por España, lo que se lograría mediante la afirmación de los principios republicanos.

Lanz gestionaría, en fin, el reconocimiento de la independencia, ofrecería igualdad de condiciones en los tratados de paz, amistad, comercio y navegación que se firmaran con otras naciones, con excepción de España, a la que podría favorecerse en compensación e] reconocimiento de la independencia. Iniciaría también propuestas para una convención consular y otra para la abolición del tráfico de esclavos, en términos de reciprocidad e igualdad absolutas. Si se le reprochaba que no se hubiesen enviado antes otros comisionados con tales propuestas, como se había hecho con Gran Bretaña, señalaría que los colombianos que habían llegado allí por motivos particulares habían sido compelidos por la policía a presentarse ante la embajada española, contrastando así con la hospitalidad ofrecida a los súbditos franceses en Colombia. El historiador Urrutia agrega que debía también sondear la actitud de ese gobierno frente a la probable acción de Colombia en favor de la independencia de Cuba y de Puerto Rico.

En la capital francesa Lanz tuvo entrevistas con el ministro Jean Baptiste Villele, jefe del gabinete. La posición política de Villele presentaba varias dificultades a la gestión del emisario; en efecto, el ministro representaba a los ultrarrealistas, empeñados en 
vengar los agravios sufridos por el Borbón español en el período constitucionalista de 1820-1823, y consolidar así los regímenes legitimistas de las monarquías euiopeas. No obstante, Villele oponía reservas a esa actitud, en atención a la probable reacción que clla podía provocar por parte de Gran Bretaña. El propósito primordial de Villele era restablecer el antiguo régimen de manera paulatina, y a ello subordinó toda su política, incluso la internacional. El eclecticismo necesario para llevar adelante el plan provocaría su caída en 1827 por obra de los liberales y ante la falta de apơyo de los ultracatólicos, que nunca aceptaron su actitud contemporizadora.

Las tentativas de Lanz ante Villele se enmarcaron dentro de este cuadro político europeo. La síntesis que presenta Urrutia de tales gestiones se compatibiliza perfectamente con la posición de Villele; dice el autor colombiano que Lanz encontró en el ministro francés buena disposición y recibió la promesa de mediar para llegar a un armisticio con España, pero que también encontró cautela en razón de la amistad francesa con la Corona española.

La primera entrevista debió realizarse en marzo de 1825, pues es informada por Lanz al gobierno colombiano en nota del 31 de ese mes. En esa entrevista la atención fue puesta en el empeño de Lanz por desmentir el concepto sobre la revolución colombiana, a la que se veía como anárquica, destructiva y cruel con los enemigos, y también como acomodaticia en su política exterior. El recelo francés, naturalmente, era por la preeminencia e influjo de la Gran Bretaña sobre los nuevos gobiernos hispanoamericanos. La principal preocupación de Lanz, esto es acreditar las intenciones de constituir la nación y darle instituciones ordenadas, contrastan con la posición de años antes frente a la revolución rioplatense, cuando reveló en Francia su desencanto por el cariz anárquico y desordenado en que ésta se debatía.

Luego de esa primera conferencia con Villele, Lanz recibió nuevas instrucciones del gobierno colombiano conteniendo reflexiones acerca de cómo instar a Francia a desvincularse del compromiso de apoyo a la monarquía española, para dejar así a ésta 
librada a su suerte ${ }^{60}$ Lanz debía enfrentar también quejas concre. tas del gobierno francés por el control y requisa que revolucionarios venezolanos habían practicado sobre barcos franceses frente a Portobelo. "Villele sostenía que el pabellón libre tornaba igualmente libres las mercancías enemigas transportadas en sus embarcaciones, tesis que el gobierno colombiano no aceptó, replicando que Francia misma la había desestimado en sus prácticas marítimas en épocas de guerra; Lanz argumentó que el beligerante tiene el derecho de confiscar las propiedades enemigas encontradas en buques neutrales, derecho al que Colombia había renunciado en el tratado de comercio y navegación firmado con los Estados Unidos, prometiendo igual privilegio a Francia si se decidiera a iniciar relaciones de nación a nación con Colombia.

Las gestiones merecieron el beneplácito de su gobierno, en tanto alternaba su tiempo en tareas diversas relacionadas con la Gran Colombia. Sin duda, los triunfos de Bolívar y Sucre en Perú cambiaron las demandas del gobierno colombiano en Europa, y Lanz pudo asumir una actitud más segura y confiada ante el gobierno francés. Es probable que luego de sus primeras gestiones, encargadas antes de la victoria de Ayacucho, se mantuviera a la espera para observar la nueva actitud de las potencias europeas ante el ya irreversible triunfo de las armas revolucionarias.

Gual renovó las instrucciones, en mérito a los sucesos que se producían y a los informes del agente en Francia; en septiembre de 1825 le encargó sondear la opinión del gobierno francés en caso de que Colombia llevase a cabo una expedición contra el poder español en Cuba y Puerto Rico. ${ }^{62}$ La situación de ambas islas era considerada entonces con extremo cuidado por Gran Bretaña, recelosa de que, sobre todo Cuba, quedase luego de su emancipación política bajo el control de los Estados Unidos. También provocaba reservas del gobierno norteamericano, pues el triunfo revolucionario en Cuba acarrearía la abolición de la esclavitud, ocasionando

60 A.N.C., Colecciones. E. Ortega Ricaurte, Caja 220. Del gobierno de Colombia a Lanz. 19 de julio de 1825 . (Copia).

61 Se trataba de la detención de los bergantines aLa Gaselle», por sospechoso de piratería, y del «Uranie», que transportaba propiedades de enemigos.

62 Mendoza: Misión de José María Lanz. 
una peligrosa situación para su régimen de explotación de mano de obra en un país vecino.

Por ese año 1825 Lanz se ocupó en tratar de reivindicar el nombre de Francisco Antonio Zea, su benefactor de años antes, a instancias de la viuda del político, mientras Hurtado y Revenga se ocupaban de reunir antecedentes para probar sus acusaciones de malversación de fondos. ${ }^{63}$ También en ese año recibió el encargo de Hurtado de contratar la acuñación de una medalla en homenaje a Bolívar por sus triunfos en el Perú. Lanz concertó y supervisó el tratado realizado con el grabador Raimond Gairard. ${ }^{64}$

En tanto, Revenga había reemplazado a Gual en la conducción de las relaciones exteriores de la Gran Colombia; el nuevo ministro confiaría a Lanz la tarea de interesar a Francia acerca de la importancia del Congreso de Panamá, reunión largamente deseada por Bolívar y cuya concreción tendría a Gual como principal organizador. ${ }^{65}$ Ya habían sido invitados los Estados Unidos y la Gran Bretaña, y ahora Lanz debía hacer saber a aquel gobierno que sería bien recibido un comisario francés en el Congreso, con la advertencia que el fin esencial era asegurar la independencia de los nuevos países.

Urrutia afirma que las actividades de Lanz cesaron en abril de 1826. Sin embargo, tenemos referencias sobre su actividad oficial luego de esa fecha. Como lo señala Mendoza, el 3 de abril de 1826 fue nombrado José Fernández Madrid en su reemplazo, pero éste llegaría a París recién en agosto.

El 11 de mayo Lanz tuvo una importante entrevista con Villele, en cumplimiento de instrucciones y de una acción concertada con la que Hurtado desarrollaba en Londres ante Canning. Ambos propusieron la intervención de las dos potencias para el caso que España, a pesar de sus derrotas en el Perú, se obstinase en no querer

63 A.N.C., República. Miscelánea, tomo 31, fol. 756. De Felipe Zea a José de Lanz. Paris, 15 de mayo de 1825.

64 A.N.C., República. Miscelánea, tomo ¿3, fol. 994 y vta. Contrato entre José de Lanz y Raimond Gairard. París, 19 de septiembre de 1825.

65 Menđoza: Misión de José Maria Lanz. 
reconocer la independencia de los países hispanoamericanos; el objeto era, en tal caso, firmar una tregua o suspensión de hostilidades por el término de diez hasta veinte años. ${ }^{66}$ Ahora Villele se mostró ampliamente dispuesto en favor de las pretensiones colombianas, al igual que Canning. Los dos ministros se comprometieron en dar instrucciones al respecto a sus embajadores ante la Corona española. De todos modos, los colombianos no lograron la aprobación de su gestión por el gobierno mexicano, ante cuyo representante gestionaron una posición solidaria. El ministro de Relaciones Exteriores mexicano, Lucas Alamán, sintió afectados los intereses de su país, pues la tregua propuesta significaba un acuerdo bilateral entre Colombia y España que desprotegía y aislaba la causa de la revolución mexicana. Alamán consideró violado el pacto entre Colombia y México, que establecía no entrar en tratados con España sin velar por los intereses recíprocos de las naciones hispanoamericanas. ${ }^{67}$

Obsérvese que en los mismos días de estas gestiones, se celebraba en Panamá el Congreso convocado por Colombia y Perú, cuyo objetivo principal era concertar una acción y una estrategia comunes para sostener la independencia de estos países. Las gestiones de Hurtado en Londres y de Lanz en París debían ser vistas como una flagrante contradicción con los principios sostenidos en Panamá.

Las desinteligencias entre Colombia y México tenían aún una causa anterior y más eficiente: el recelo mexicano hacia las miras de apropiación que tenían los proyectos colombianos de sustraer a Cuba y Puerto Rico de la dominación española. La política antillana de la Gran Colombia despertó también los recelos de los

66 De Vicente Rocafuerte al secretario de Relaciones Exleriores de México. Londres, 7 de junio de 1826. En Peña y Reyes, Antonio de la: El Congreso de Pana. má y alounos otros proyectos de Unión Hispano-americana. México (Archivo Histórico Diplomático, núm. 19), 1926, págs. 22-26. Vid también Drago, Mariano José: El Congreso de Panamá. Buenos Aires, 1970.

67 Del secretario de Relaciones Exteriores de México a Vicente Rocafuerte. México, 10 de agosto de 1826. En Peña y Reyes: El Congreso de Panamá..., págs. 26-31. 
Estados Unidos, que ya tenían en sus miras la expansión hacia las islas y el mar antillanos. El representante estadounidense en París, James Brown, trabajó para estorbar los planes colombianos, que Lanz representaba. ${ }^{68}$

La tregua gestionada por Lanz, como se ve, dejaría libres los ejércitos ded Colombia para extender la revolución hacia el Caribe, como ya lo había hecho hacia los Andes Meridionales. $\mathrm{Y}$ esto no convenía a Gran Bretaña, ni a Estados Unidos, ni a Francia, ni a México. Ante tantos opositores, es fácil deducir las razones por las que las gestiones no fueran más adelante que de las meras expresiones de buena voluntad.

Aquí debieron terminar los trabajos de Lanz en favor de la emancipación colombiana. Pronto se agravaría de su dolencia; su mujer también estaba muy enferma. En marzo de 1827, se quejaba de no recibir sus sueldos desde muchos meses atrás. Estaba previsto su regreso a Colombia, pero sin duda no estaban dadas las condiciones.

El nuevo representante colombiano, José Fernández Madrid, se interesó por su suerte, y escribió a su gobierno poniendo de relieve su patriotismo y honorabilidad. ${ }^{69}$ Lanz había pedido formalmente fuese asistido para salir de su postración económica hasta «su regreso» a Colombia, pero es probable que no estuviese en sus miras regresar realmente. No hubo satisfacción a sus demandas, en las que persistió hasta 1829. Fernández Madrid había comprometido también la ayuda de José Manuel Restrepo, para cuya historia Lanz había colaborado con la confección del Atlas. Restrepo, que se desempeñaba entonces en la secretaría de Relaciones Exteriores, no tomó con mucha convicción el asunto, pues se limitó a pasar la petición de Fernández Madrid al secretario de Guerra. La resolución de éste fue expeditiva, al disponer que «el gohicrno no tiene empleado en Francia a este Coronel ni puede hacerlc alli tá, 1961 .

68 Rivas, Raimundo: Historia diplomática de Colombia (1810-1934). Bogo-

69 A.N.C., República, Guerra y Marina, tomo 1.427, fol. 781. De José Fernández Madrid al secretario de Relaciones Exleriores de la Gran Colombia. París, 11 de marzo de 1827.

I'omo XLVII 
el pago de sueldos; si se restituye a Colombia será destinado, o recibirá letras de cuartel, según convenga al servicio». ${ }^{70}$

Bolívar dio más tarde una orden lapidaria: «que si no se le han dado aún, se le espidan desde luego sus letras de retiro, sin ningún género de pensión, y se le separe de toda intervención y conocimiento en los negocios de Colombia, pues que ésta absolutamente no necesita de los servicios de aquel Gefe». ${ }^{71}$ La Secretaría de Relaciones Exteriores se ocupó en dar término a la cuestión enviando a Fernández Madrid las letras de retiro de Lanz. ${ }^{72}$

Los ministerios de Guerra y de Relaciones Exteriores se habían pasado así el asunto de uno a otro, terminando ambos por lavarse las manos. Sólo Fernández Madrid, que había visto la doliente situación de Lanz, se había conmovido por ella, pero no había encontrado eco en ninguna otra persona del gobierno. Así concluyeron los servicios de Lanz a Colombia, sin un agradecimiento por los servicios prestados, y sin recibir sus sueldos de militar, de diplomático o de científico. Sin embargo, había trabajado con inteligencia, lealtad y provecho en favor del desarrollo científico y de la afirmación de la independencia colombiana. En todo caso, los errores que a juicio de las autoridades de turno cometió, fueron la consecuencia de las mutaciones de criterios de los gobernantes que le encomendaron sostener en Europa la causa de la revolución.

Desde cierta perspectiva, cabe ver a Lanz como una víctima de las circunstancias políticas. Cumplió una misión difícil, y al cabo de las vicisitudes de la política internacional y la suerte de la guerra revolucionaria tornaron impolítica y desaconsajable la posición que se le había mandado sostener ante el gobierno francés.

Unos años después, Venezuela envió a Gran Bretaña y Francia a Mariano Montilla, con la investidura de Enviado Extraordinario. Montilla demandaría a ambas naciones sus buenos oficios para ob-

70 A.N.C., República, Guerra y Marina, tomo 1.425, fol. 780. De Restrepo al secretario de Guerra. Bogotá, 13 de julio de 1827. Minuta del Secretario de Guerra. Bogotá, 3 de marzo de 1828.

71 A.N.C., República, Guerra y Marina, tomo 1.049, fol. 590. De Estanislao Vergara al secretario de Guerra. Bogotá, 26 de junio de 1829.

72 A.N.C., República, Guerra y Marina, tomo 1.049, fol. 593. De Estanislao Vergara al Secretario de Guerra. Bogotá, 1 de julio de 1829. 
tener el reconocimiento de la independencia por España, o en su defecto un tratado de tregua. ${ }^{73}$ Como se ve los mismos o muy parecidos términos de la misión de Lanz. Habían transcurrido nueve años desde el comienzo de la gestión del matemático, pero Venezuela reiteraba las fórmulas para terminar con su proceso revolucionario, que finalmente culminaría en 1845 con el reconocimiento español de la soberanía de la nación venezolana. Lanz había sido protagonista de un hito significativo de ese proceso.

\section{CONClus iones}

Los trabajos de Lanz al servicio de la revolución rioplatense y de la revolución colombiana estuvieron totalmente desconectados entre sí, lo que de por sí resulta una paradoja. También han estado desvinculados hasta ahora los estudios realizados sobre esos trabajos por historiadores de Argentina con los de Venezuela y Colombia, lo que también es una paradoja, ésta corolario lógico de la primera. Esto nos conduce a la primera reflexión, referida a la continuidad, desde el origen mismo de la formación de estas naciones hasta nuestros días, de la desconexión que ha existido y existe en nuestras vidas políticas y en los estudios de nuestra realidad común.

Sin embargo, es incuestionable que lo que hizo Lanz en Buenos Aires y en Europa al servicio de las Provincias Unidas, y lo que hizo en la Gran Colombia y en Europa al servicio de la Gran Colombia guardan intrínseca vinculación en varios de sus aspectos.

La unión de los dos retazos requiere, aún, ser insertado en un más amplio cuadro de la revolución hispanoamericana en su dimensión internacional, y será entonces cuando adquiera cabal sentido integral su actividad.

Por ahora, los hechos aquí referidos muestran la desarticulación de la estrategia de los revolucionarios en política exterior, y

73 Rojas, Rafael Aımando: La politica exterior de Venezuela durante la primera administración del General Pciez. «Boletin de las Academia Nacional de la Historia», tomo LVII, núm. 226, págs. 207-217. Caracas, abril-junio de 1974. 
la preeminencia en esa materia de los recelos y las rivalidades que ya entonces se perfilaban para las posteriores relaciones entre las nuevas naciones de América. En principio, Lanz hubiera sido un interesante nexo entre Colombia y el Río de la Plata, por sus conocimientos y vinculaciones en uno y otro país, pero se prefirió destacarlo a Europa, que era el centro adonde convergían los revolucionarios en observancia del movimiento concéntrico mundial.

Los estudios científicos de Lanz quedaron frustrados en uno y otro destino. La obvia reflexión es que aún no estaban dadas las condiciones para que esfuerzos como el suyo pudieran ser debidamente aprovechados, no obstante los empeños de quienes, como Rivadavia en el Plata y Zea en Colombia, estaban convencidos que una verdadera emancipación debía comprender también la ilustración y el desarrollo de las inteligencias; visto retrospectivamente, era una lección para las futuras generaciones que aún debe ser aprendida por buena parte de los dirigentes hispanoamericanos.

Pero por encima de todas las reflexiones, preferimos dejar para el final, y a manera de colofón que, entonces como ahora, la indiferencia demostrada por la suerte de otras revoluciones o de otros procesos liberadores en la América española es una muestra lamentable de que el recelo por cuestiones vecinales relativamente menores, fue y es mayor y más fuerte que el que despertaban y despiertan los actos de las potencias imperialistas que - como entonces Francia y Gran Bretaña- disfrazaban sus propósitos hegemónicos con máscaras que daban la apariencia de benevolente protección.

Edmundo A. Heredis 